\title{
Changes in bovine leukemia virus serological status and lymphocyte count between dry-off and early lactation in Michigan dairy cows
}

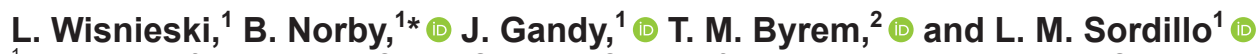 \\ ${ }^{1}$ Department of Large Animal Clinical Sciences, College of Veterinary Medicine, Michigan State University, East Lansing 48824 \\ ${ }^{2}$ CentralStar Cooperative, Lansing, MI 48909
}

\begin{abstract}
This study addresses how the serological status of bovine leukemia virus (BLV) and lymphocyte count fluctuate from dry-off to early lactation in dairy cattle. Very few studies have investigated how BLV antibody status and lymphocyte count of cows changes longitudinally during the lactation cycle. Blood samples were collected from dairy cattle $(\mathrm{n}=149)$ on 5 commercial dairy herds in Michigan at dry-off, close-up, and 7 to $10 \mathrm{~d}$ after calving. Plasma was analyzed for anti-BLV antibodies using a BLV-ELISA and whole blood was analyzed for lymphocyte counts. We found that BLV seroprevalence increased from dry-off $(38.9 \%)$ to closeup $(43.6 \%)$, then slightly decreased from close-up to 7 to $10 \mathrm{~d}$ after calving (43.0\%). However, the change in seroprevalence was only significant from dry-off to close-up. Cows of third or higher parity were more likely to seroconvert than cows of lower parity and had the highest ELISA-negative prevalence of BLV. Lymphocyte counts were significantly higher in ELISApositive animals, but only among second and third or greater parity animals. These results indicate that the use of lymphocyte counts as a disease severity monitoring tool for BLV should differ by parity group. Future studies should investigate if changes in seroprevalence are due to new infections or natural changes in antibody concentrations as the cow prepares for colostrum production. More accurate lymphocyte guidelines to be used for monitoring the progression of BLV should be created that consider parity and lactation stage.
\end{abstract}

Key words: dairy cow, bovine leukemia virus, transition period, lymphocyte count

\section{INTRODUCTION}

Bovine leukemia is a chronic oncogenic retroviral disease of cattle caused by bovine leukemia virus (BLV;

\footnotetext{
Received November 2, 2019.

Accepted April 20, 2020.

*Corresponding author: norby@msu.edu
}

Kettmann et al., 1976). Bovine leukemia virus is a delta-retrovirus (OIE, 2018) that causes a persistent lifelong infection with various clinical outcomes, such as reduced longevity (Bartlett et al., 2013), milk production (Ott et al., 2003; Erskine et al., 2012a; Norby et al., 2016), and immune function (Gillet et al., 2007; Erskine et al., 2011a,b). The virus infects B lymphocyte cells, but after a few weeks the immune response strongly limits infection of new cells. Approximately $70 \%$ of BLV-infected cattle have normal hematological parameters (aleukemic), whereas around 30\% of infected cattle experience a polyclonal proliferation of B lymphocytes, which results in a lasting increase in the number of circulating lymphocytes (Esteban et al., 1985; Bienzle, 2011). This state of increased lymphocyte counts is referred to as persistent lymphocytosis (Bendixen, 1963; Kabeya et al., 2001). Lymphoma, which is cancer of the lymph nodes, develops in 0.1 to $10 \%$ of cows infected with the virus (Kabeya et al., 2001) and is the most common cause for condemnation of dairy cattle at slaughter (White and Moore, 2009).

During a normal lactation cycle, dairy cattle experience many physiologically stressful events, such as decreased DMI and negative energy balance, that may lead to immune dysfunction (Mallard et al., 1998; Sordillo and Mavangira, 2014). Immune dysfunction leads to increased risk of transition diseases (Goff and Horst, 1997; Sordillo and Raphael, 2013), but may also increase susceptibility to other infections, including BLV. The immunosuppression that occurs around parturition may significantly decrease BLV antibody titers (Burridge et al., 1982; Mallard et al., 1998). Burridge et al. (1982) previously showed that BLV antibody titers significantly decreased after calving compared with precalving, using both an immunodiffusion test with a glycoprotein antigen and a radioimmunoprecipitation assay with an internal p24 protein antigen. In addition, lymphocyte counts have been shown to fluctuate in response to events during the lactation cycle, including dry-off (DO) and calving (Kehrli et al., 1989; Goff and Horst, 1997; Putman et al., 2018). However, only a few studies have examined how BLV antibody status 
and lymphocyte counts change longitudinally during the lactation cycle. Understanding how BLV antibodies and lymphocyte counts fluctuate over time may lead to improved detection, prevention, and diagnosis.

The objective of this study was to determine how BLV status, measured using BLV-ELISA, and lymphocyte counts change during the lactation cycle and by parity. To address this objective, we determined BLV status at DO, close-up (CU), and 7 to 10 DIM (DIM7) in dairy cows sampled at commercial Michigan farms.

\section{MATERIALS AND METHODS}

\section{Animals}

This study was a secondary analysis of a previously described project (Wisnieski et al., 2019). Dairy farms were eligible if they had more than 1,000 lactating cows, had all Holstein cows, used Dairy COMP305 (Valley Agriculture Software, Tulare, CA) or PCDART (Dairy Records Management Systems, Raleigh, NC), artificially bred cows, and separated cows for CU. In short, 100 heifers and 200 cows from 5 commercial dairy herds in Michigan were enrolled. The original sample size calculation is presented in detail in Wisnieski et al. (2019). Animals were enrolled in cohorts based on their expected calving date. Enrollment of cows was at the time of DO and for heifers the equivalent length of time before calving. Cohorts of 15 animals consisted of 3 groups of 5 animals: 5 heifers $<25$ mo old, 5 cows entering their second lactation, and 5 cows entering their third or greater lactation at calving to obtain a representative sample of the underlying population. Within each lactation group, the animals were selected at random from the pen from the list of all healthy cattle that were to be dried off that week. At the time of DO, cows were approximately 200 to $230 \mathrm{~d}$ pregnant and $<380$ DIM. The health status of animals was monitored during the dry period through the first $30 \mathrm{~d}$ after calving. For the current analysis, only animals that had complete data for both BLV-ELISA and lymphocyte counts for all 3 sample points were included, so that the changes in BLV status between sample points could be assessed. In addition, animals that had any of the following disease events were excluded: mastitis, metritis, ketosis, retained placenta, displaced abomasum, pneumonia, lameness, milk fever, died, had a calf that died, or aborted.

The study and protocols were approved by the Institutional Animal Care and Use Committee (Animal Use Form \#: 03/17-033-00) at Michigan State University (East Lansing).

\section{BLV-ELISA and Hematologic Testing}

Blood samples were collected in two 6-mL $\mathrm{K}_{2}$-EDTA tubes (Vacutainer, BD Diagnostics, Franklin Lakes, NJ) from the tail vein or artery of animals at the time of DO, within $7 \mathrm{~d}$ of entering the CU group, and within 7 to $10 \mathrm{~d}$ postcalving (DIM7). Movement to CU group occurred $\sim 21 \mathrm{~d}$ to expected calving date and occurred weekly.

After collection, plasma was extracted, pooled, and then stored at $-80^{\circ} \mathrm{C}$ until ELISA analysis for antiBLV antibodies. The ELISA analysis was performed at CentralStar Cooperative (Lansing, MI) and followed the manufacturer's instructions (Simard et al., 2000). The cut-off for positivity on the ELISA was an optical density $>1.0$ (CentralStar, 2019). The sensitivity and specificity of the ELISA relative to the agar gel immunodiffusion test (used as the gold standard) are $99.8 \%$ and $100 \%$, respectively (Simard et al., 2000). The ELISA test used has extremely high agreement (Cohen's kappa >0.93) with other ELISA assays (Kuczewski et al., 2018) and is able to detect antibodies in samples up to a dilution of 1/5,000 (Simard et al., 2000). More information about the ELISA test and properties is presented in Walsh et al. (2013).

Whole blood was submitted for leukocyte counts within $24 \mathrm{~h}$ of collection. Total and differential leukocyte counts were conducted at the Advanced Animal Diagnostics (Morrisville, NC) using Wright stain. Absolute concentrations of leukocyte populations were calculated by multiplying the total leukocyte concentration by the relative percentage of subpopulations. Neutrophil and lymphocyte counts were reported for the purpose of this study.

\section{Statistical Analyses}

Data management and descriptive statistics were performed in Stata version 15.1 (StataCorp, College Station, TX), multivariable models were built in SAS version 9.4 (SAS Institute Inc., Cary, NC), and figures were created in $\mathrm{R}$ version 3.4.1 (The $\mathrm{R}$ Foundation, Vienna, Austria).

Descriptive Statistics. Descriptive statistics for lymphocyte counts and ELISA-negative (ELISA-) prevalence were calculated for each sampling time (DO, CU, and DIM7). Prevalence was presented as point estimates and $95 \%$ confidence intervals using the exact method (Stata, 2017). Changes in ELISA status between 2 consecutive sampling times (DO to $\mathrm{CU}$ and CU to DIM7) are presented as proportions. Only cows negative on a previous sampling were used to calculate 
the proportion of cows becoming positive at the consecutive sampling time and vice versa for cows changing status from positive to negative. Significant differences between the proportion of animals that seroconverted from DO to CU and from CU to DIM7 were tested using a chi-squared test or Fisher's exact test if cell counts were $<5$. Descriptive statistics were stratified by parity group if it was determined that parity group was significantly related to the variable(s) of interest in the multivariable analyses. Neutrophil counts were reported alongside lymphocyte counts in descriptive analyses.

Multivariable Analyses. Two multivariable repeated measures models were built. The first model assessed what factors were associated with BLV-ELISA status (which could vary by time point within animal). This was a mixed effects logistic model using PROC GLIMMIX in SAS with a binomial distribution and a logit link, because the outcome (ELISA status) was binary $(0=$ negative vs. $1=$ positive $)$. Covariates for modeling included sample time in days, parity group $(1,2$, or 3 or greater $)$, and a sample time and parity group interaction term. Because time between sample points was different for each cow, the average time from DO for each sample point was calculated for use in modeling correlation of residual in longitudinal models: DO (d 0), CU (d 32), and DIM7 (d 55). Backward elimination using an $\alpha$ of 0.05 was performed to select the variables in the final model. Sample time in days was forced into the model.

The second multivariable model was used to assess what factors were associated with lymphocyte counts using a mixed effects linear model in PROC MIXED in SAS. Covariates eligible for entry into the model included sample time in days, parity group $(1,2,3+$ lactation $)$, ELISA status $(0=$ negative, $1=$ positive, which may vary by time point within animal), and all possible 2-way interactions. Backward elimination using an $\alpha$ of 0.05 was used to select the variables in the final models. Sample time in days was forced into this model so that change in lymphocyte counts over time could be assessed. The normal distribution of lymphocyte counts and residuals were assessed via histograms and Q-Q (quantile over quantile) standardized residual plots. Heteroskedasticity of residuals by each factor variable in the final model was visually checked using box plots. Degrees of freedom were estimated with the Kenward-Rogers approximation.

To account for unequally spaced sample times in both multivariable models, correlation between residuals was modeled using the spatial power covariance structure in both models. Multiple comparisons between categories of covariates were performed with a Bonferroni adjustment. To account for the hierarchy and structure of the data, random effects for the intercepts of herd, cohort, and cow were retained in the model unless their variance estimates were estimated to be 0 .

\section{RESULTS}

\section{Descriptive Data}

From the original 300 cows that were enrolled, blood samples at DO were successfully collected from 283 cows from September 24, 2014, to December 15, 2015. The number of cows with complete BLV-ELISA and lymphocyte count data on all 3 sampling days (DO, CU, and DIM7) was 218. After exclusion of animals with negative health outcomes as stated in the methods, the final sample included 149 animals. The number of cows with lactations 1, 2, and 3+ were 58 (38.9\%), 53 $(35.6 \%)$, and 38 (25.5\%). Lymphocyte counts by sample period and lactation group $(1,2$, and $3+)$ are shown in Figure 1. Lymphocyte counts among ELISA-positive (ELISA+) animals were higher than ELISA - animals at each time point and among each parity group, except for among second parity cattle at DO. Interestingly, neutrophil counts were not significantly different $(P>$ $0.05)$ between ELISA + and ELISA - animals except among second parity cattle at DO $(P=0.04$; Table 1$)$.

At DO, the overall percentage of cattle that were ELISA + was $38.9 \%$, which increased to $43.6 \%$ at CU and slightly decreased to $43.0 \%$ at DIM7. Across all sample points, the prevalence of ELISA+ animals was highest among cattle in third or greater lactation group $(67.5 \%)$, followed by second lactation cattle (41.5\%) and first lactation cattle (25.3\%).

A greater proportion of ELISA - animals changed to ELISA+ from DO to CU compared with CU to DIM7,

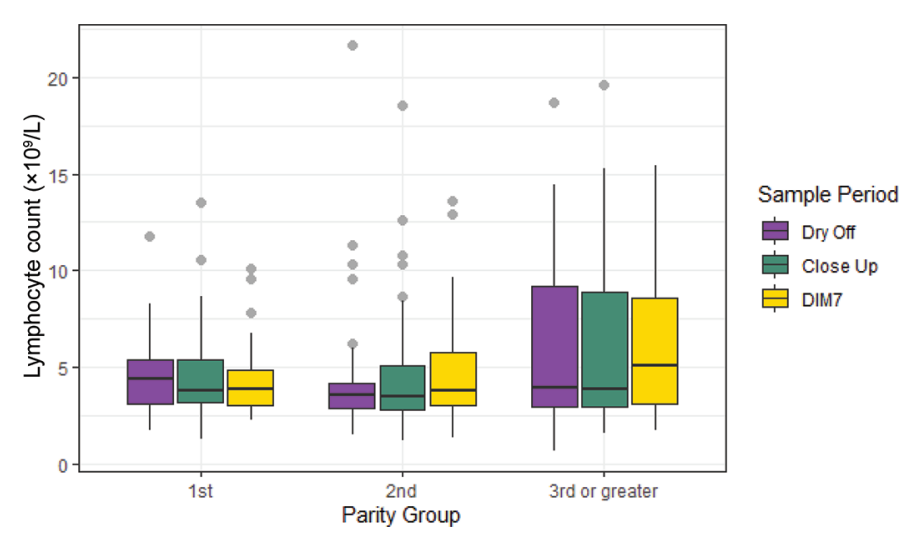

Figure 1. Lymphocyte counts $\left(\mathrm{LC} ; \times 10^{9} \mathrm{LC} / \mathrm{L}\right)$ by parity group and sample time [dry-off, close-up, and $\sim 7$ DIM (DIM7)] in a sample of 149 cattle from 5 commercial dairy herds in Michigan. Box: interquartile range $(\mathrm{IQR})$. Black horizontal line: median. Whiskers: $1.5 \times$ IQR. Gray circles: values outside whiskers. 
Table 1. Lymphocyte and neutrophil count $\left(\times 10^{9} / \mathrm{L}\right)$ by parity, bovine leukemia virus ELISA status (positive, ELISA+; negative, ELISA-), and sample time (dry-off, close-up, and DIM7 ${ }^{1}$ ) in a sample of 149 cattle from 5 commercial dairy herds in Michigan

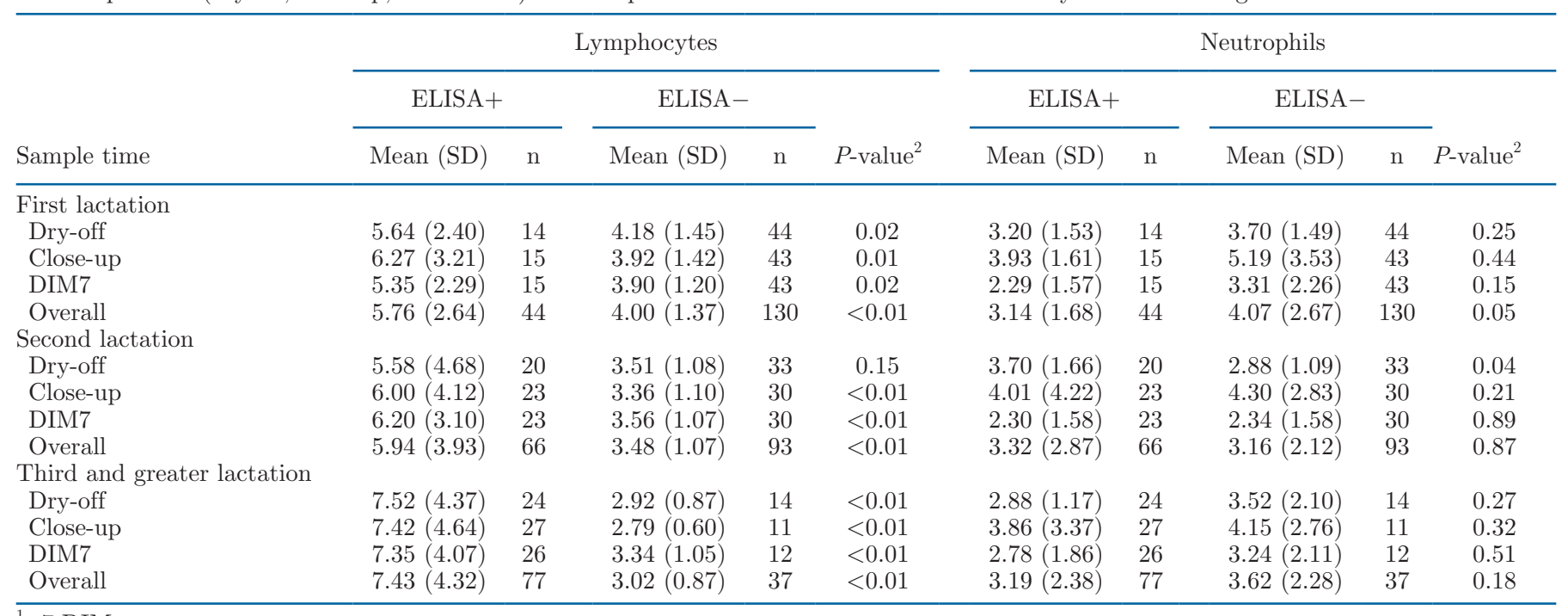

${ }^{1} \sim 7$ DIM.

${ }^{2} P$-value for comparison of ELISA+ versus ELISA - animals within row and cell type (i.e., lymphocyte or neutrophil). Comparisons were analyzed using the Kruskal-Wallis test.

although not significantly different (Table 2). By parity group, the proportion of animals changing status from ELISA - at DO to ELISA + at CU in each parity group $(1,2$, and $3+)$ was $2.3 \%, 9.1 \%$, and $21.4 \%$, respectively, with $3+$ parity cattle significantly more likely to seroconvert than first parity. From CU to DIM7, 0\%, $10 \%$, and $0 \%$ of cattle in the first, second, and third or greater parity groups became ELISA+, with second parity cattle significantly more likely to seroconvert than first or third or greater parity cattle. The ELISA optical density values for cattle that changed BLVELISA status during the study period are reported in Supplemental Table S1 (https://doi.org/10.3168/jds .2019-17839).

The proportion of animals changing status from ELISA + to ELISA - from DO to CU and from CU to DIM7 were $0 \%$ and $6.2 \%$, respectively (Table 2). Among the 12 animals that were ELISA+ at CU but were ELISA - at DIM7, 9 were of second parity, and 3 were of $3+$ parity.

\section{Multivariable Models}

BLV-ELISA Status. Mixed logistic regression results are shown in Table 3. The final model included sample time in days $(P=0.04)$ and parity group $(P<$ $0.01)$. The probability of being ELISA+ increased after DO, but only the probability of being positive at $\mathrm{CU}$ was significantly greater compared with DO (adjusted $P=0.03)$. Odds of being ELISA + also increased with parity group and were significantly greater among those in their third or greater lactation (1 vs. $3+: P<0.01$; 2 vs. $3+: P=0.04)$.

Lymphocyte Counts. Mixed effects linear regression results for lymphocyte counts are shown in Table 4. Lymphocyte counts were transformed by the log

Table 2. Proportion of cattle that changed or stayed the same in bovine leukemia virus ELISA status between 2 consecutive sample times (dry-off to close-up and from close-up to DIM7 $7^{1}$ ) in a sample of 149 cattle from 5 commercial dairy herds in Michigan

\begin{tabular}{|c|c|c|c|}
\hline Sample time & $\begin{array}{l}\text { Negative to positive } \\
\text { proportion }(95 \% \mathrm{CI})\end{array}$ & $\begin{array}{l}\text { Proportion stayed the } \\
\text { same }(95 \% \mathrm{CI})\end{array}$ & $\begin{array}{l}\text { Positive to negative } \\
\text { proportion }(95 \% \mathrm{CI})\end{array}$ \\
\hline Dry-off to close-up & $7.7(2.2-13.2)$ & $95.3(91.9-98.7)$ & $0\left(0.0-6.0^{2}\right)$ \\
\hline Close-up to DIM7 & $3.6(0.0-7.5)$ & $95.3(91.9-98.7)$ & $6.2(3.1-12.0)^{*}$ \\
\hline
\end{tabular}


Table 3. Multivariable mixed effects logistic regression results for bovine leukemia virus ELISA status in a sample of 149 cattle from 5 commercial dairy herds in Michigan ${ }^{1}$

\begin{tabular}{lccc}
\hline Variable & Estimate & SE & $P$-value \\
\hline Sample time & Referent & - & 0.04 \\
Dry-off (d 0) & 0.22 & 0.22 & 0.01 \\
Close-up (d 32) & 0.19 & 0.19 & 0.09 \\
$\sim 7$ DIM (d 55) & & & $<0.01$ \\
Parity group & Referent & - & - \\
First & 0.75 & 0.4 & 0.06 \\
Second & 1.79 & 0.44 & $<0.001$ \\
Third or greater & -1.25 & 0.32 & 0.02 \\
Intercept &
\end{tabular}

${ }^{1}$ Covariance parameter estimates, percent of total covariance: farm $(0.07,3.4 \%)$, spatial power covariance matrix for repeated measures $(1.00,48.0 \%)$, and residual $(1.01,48.71 \%)$.

function (base 10) to meet linearity assumptions. The final model included sample time, parity group, ELISA status, and a parity and ELISA status interaction term. Lymphocyte counts were not significantly different between the 3 sample times $(P=0.29)$. The parity and ELISA status interaction term indicated that lymphocyte counts were significantly greater in ELISA+ animals compared with ELISA - animals, but only among second and third or greater parity cattle (Figure 2). Lymphocyte counts among ELISA + animals were not

Table 4. Multivariable mixed linear regression results for $\log _{10}\left(\right.$ lymphocyte count $\left.\times 10^{9} / \mathrm{L}\right)$ in a sample of 149 cattle from 5 commercial dairy herds in Michigan ${ }^{1,2}$

\begin{tabular}{lccc}
\hline Variable & Estimate & SE & $P$-value \\
\hline Sample time & Referent & - & 0.29 \\
Dry-off (d 0) & -0.01 & 0.01 & 0.55 \\
Close-up (d 32) & 0.01 & 0.01 & 0.33 \\
７ DIM (d 55) & & & 0.35 \\
Parity group & Referent & - & - \\
First & -0.08 & 0.04 & 0.05 \\
Second & -0.15 & 0.05 & $<0.01$ \\
Third or greater & Referent & - & $<0.01$ \\
ELISA status & 0.11 & 0.05 & 0.02 \\
0 & & & $<0.01$ \\
1 & & & \\
Parity and ELISA status & & - & - \\
interaction term & Referent & - & - \\
First parity and ELISA & Referent & - & \\
0 & & & - \\
1 & Referent & - & 0.52 \\
Second parity and ELISA & 0.04 & 0.06 & - \\
0 & & & - \\
1 & Referent & - & 0.001 \\
$3+$ parity and ELISA & 0.22 & 0.07 & $<0.001$ \\
0 & 3.60 & 0.04 & \\
1 & &
\end{tabular}

${ }^{1}$ Covariance parameter estimates, percent of total covariance: farm $(0.005,0.49 \%)$, cohort $(0.001,0.10 \%)$, spatial power covariance matrix for repeated measures $(0.98,95.6 \%)$, and residual $(0.036,3.51 \%)$.

${ }^{2} \log _{10}\left(\right.$ lymphocyte count $\left.\times 10^{9} / \mathrm{L}\right)$ multiplied by 1,000 to improve interpretability of the results.

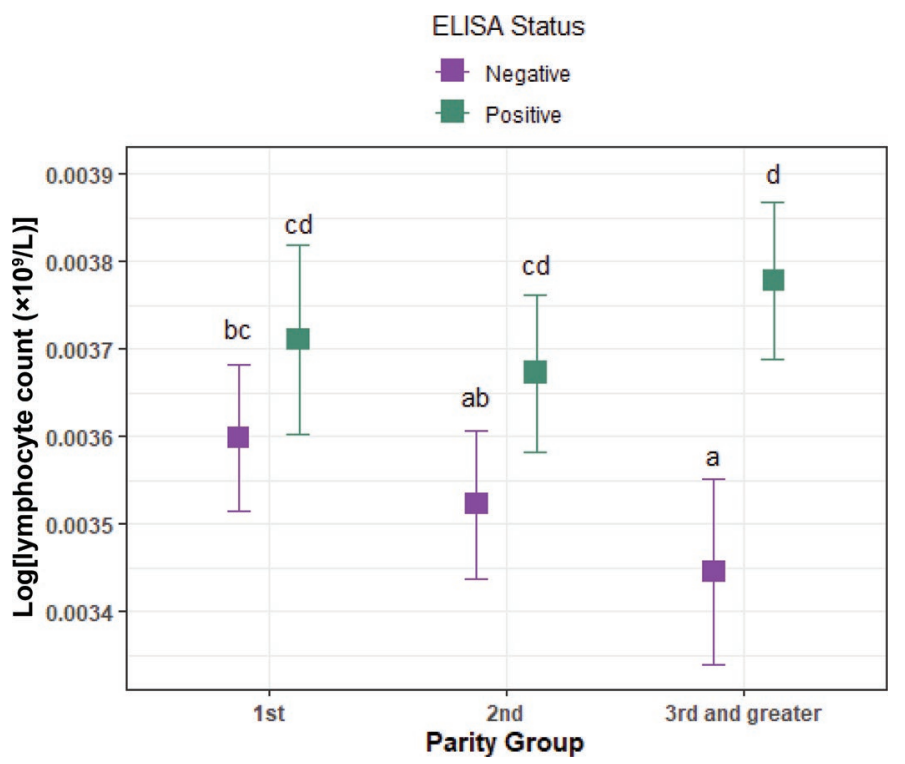

Figure 2. Least squares means estimates from the mixed effects linear regression model for $\log _{10}\left(\operatorname{lymphocyte}\right.$ count; $\left.\times 10^{9} / \mathrm{L}\right)$ by parity group and bovine leukemia virus ELISA status in a sample of 149 cattle from 5 commercial dairy herds in Michigan. Error bars indicate the $95 \%$ CI of the LSM. Means sharing a letter are not significantly different (Bonferroni-adjusted comparisons: $P \geq 0.05$ ).

significantly different between parity groups. Among ELISA - animals, third or greater parity animals had significantly lower lymphocyte counts compared with first parity animals.

\section{DISCUSSION}

In this prospective cohort study, we found that prevalence of BLV, determined by ELISA, increased from DO to CU and decreased from close-up to DIM7. However, significant increases of prevalence were only seen from DO to CU. The increase in the prevalence of sero-positivity could be due to increased susceptibility to BLV at this time due to the stress of DO. Dryoff causes a mild inflammatory response (Putman et al., 2018). Another reason for the increased prevalence from DO to CU could be natural changes in antibody concentrations and may not be indicative of new infections. Evidence indicates that antibodies change in concentration during the lactation cycle. Burridge et al. (1982) found that BLV antibody titers decreased after calving. However, it is still unknown whether the decrease in BLV antibodies at calving was due to increased trafficking of antibodies to colostrum (Reber et al., 2006) or an effect of immune dysfunction. In addition, Burridge et al. (1982) did not assess changes in BLV antibody concentrations from DO to CU. Last, changes in BLV status throughout the study period 
could also be attributed to false negatives or false positives in the ELISA test. Although ELISA has high sensitivity and specificity (>95\%), it is possible that cattle were misclassified (Trono et al., 2001). Unfortunately, we were unable to confirm BLV infection using other tests, such as using PCR to measure proviral load (Rola and Kuzmak, 2002).

As expected, prevalence of BLV determined by ELISA was greatest in the highest parity group (3+) (Erskine et al., 2012b) and it was consistently and significantly higher than first and second lactation cows. The third or greater parity group was more likely to seroconvert from DO to CU compared with the first parity group. A potential reason for higher rate of seroconversion in older cows compared with heifers is that older cows may be more likely to be exposed to BLV cumulatively through time. Older cattle also have reduced conception rates so are exposed to more fertility injections (Hillers et al., 1984), which can increase exposure to BLV if needles or syringes are reused (Sprecher et al., 1991). In addition, older cows may have reduced immune function (Ohtsuka et al., 2009; Wojdak-Maksymiec et al., 2013). For example, older cows are at higher risk of co-infections and other diseases and undergo increased metabolic stress due to higher milk production (Alban, 1995; Seifi et al., 2011).

Based on reference values from the literature, lymphocyte count decreases with increasing age (Roland et al., 2014). However, in this study, only older cows (3+ parity) that were ELISA - had significantly lower lymphocyte counts compared with younger cattle (first parity). Interestingly, among ELISA+ animals, no significant difference was observed in lymphocyte counts among all parity groups. It has been pointed out previously that inclusion of ELISA+ cattle in samples to determine normal values of lymphocyte counts in cattle significantly overestimated normal values (Swenson et al., 2013). Researchers have proposed different cut-offs of lymphocyte counts for BLV that are not parity or age specific. For instance, Erskine et al. (2011b) used the cut-off of $\geq 7,500$ lymphocytes to define persistent lymphocytosis cows. Age-specific lymphocyte guidelines were developed as part of efforts to eradicate the disease in Europe. For example, the Bendixen key developed in Denmark (Bendixen, 1963) provided lymphocyte guidelines based on age. However, it was produced almost $60 \mathrm{yr}$ ago so it is likely based on a study population different from the present population. To improve the use of lymphocyte counts as a tool for monitoring the progression of BLV, parity- or age-specific lymphocyte counts based on modern cattle populations may be needed.

This is the first study that assessed BLV-ELISA status longitudinally through the physiological transition from late lactation to DO and from late gestation to early lactation. This has major implications for monitoring and diagnosing BLV by serology, as our results indicate that cows can convert from BLV-ELISA+ to BLV-ELISA - in a relatively short period of time. However, a limitation of this study is that the animals were only tested at 3 time points and we did not measure proviral load, so the seroprevalence changes could not be confirmed. The BLV provirus remains detectable in infected animals even in the absence of antibodies (Tajima et al., 1998; Ohno et al., 2015). Future studies should confirm the changes in seroprevalence found in this study by measuring proviral load in addition to BLV antibodies. If seroprevalence if truly highest at $\mathrm{CU}$, monitoring from DO to $\mathrm{CU}$ may capture more cows that are truly positive, but become ELISA negative after calving.

We found that prevalence and seroconversion were highest among those in the third or greater parity group and only from DO to CU. In addition, although not significantly different, we found that prevalence decreased from CU to DIM7. Monitoring for BLV between $\mathrm{DO}$ and $\mathrm{CU}$, when risk of seroconverting is highest, could successfully capture more BLV seropositive cows that may become seronegative after calving. These findings also indicate that there may be a need to establish parity and lactation stage-specific cut-offs for lymphocyte counts to improve monitoring of BLV disease progression.

\section{CONCLUSIONS}

The prevalence of BLV, as determined by ELISA, significantly increased from DO to CU. We found that older cows had the highest prevalence of BLV and were most likely to seroconvert in the time period between DO and CU. Among ELISA - animals, third or greater parity animals had lower lymphocyte counts compared with first and second parity animals. Among ELISA+ animals, no significant differences were observed in lymphocyte counts among different parity groups. Future studies could develop parity- or age-specific lymphocyte count guidelines as a tool for monitoring BLV disease progression. In addition, future studies could assess how BLV status, and our ability to properly diagnosis it, changes throughout the lactation cycle in cattle with other infections or disease conditions.

\section{ACKNOWLEDGMENTS}

We thank Jennifer Brown (Duke University: Durham, NC) for technical help with data collection. This material is based upon work supported by the National Institute of Food and Agriculture (Washington, DC; 
USDA-National Institute of Food and Agriculture grant numbers 2014-68004-21972 and 2017-67015-26806). The authors have not stated any conflicts of interest.

\section{REFERENCES}

Alban, L. 1995. Lameness in Danish dairy cows: Frequency and possible risk factors. Prev. Vet. Med. 22:213-225. https://doi.org/10 .1016/0167-5877(94)00411-B.

Bartlett, P. C., B. Norby, T. M. Byrem, A. Parmelee, J. T. Ledergerber, and R. J. Erskine. 2013. Bovine leukemia virus and cow longevity in Michigan dairy herds. J. Dairy Sci. 96:1591-1597. https: //doi.org/10.3168/jds.2012-5930.

Bendixen, H. J. 1963. Preventive measures in cattle leukaemia: Leukosis enzootica bovis. Ann. N. Y. Acad. Sci. 108:1241-1267. https:// doi.org/10.1111/j.1749-6632.1963.tb13448.x.

Bienzle, D. 2011. Hematopoietic neoplasia. Pages 83-105 in Duncan and Prasse's Veterinary Laboratory Medicine: Clinical Pathology. 5th ed. K. S. Latimer, ed. Wiley, Chichester, UK.

Burridge, M. J., M. C. Thurmond, J. M. Miller, M. J. F. Schmerr, and M. J. Van Der Maaten. 1982. Fall in antibody titer to bovine leukaemia virus in the periparturient period. Can. J. Comp. Med. 46:270-271.

CentralStar. 2019. Leukosis final results interpretation. Accessed Apr. 4, 2020. https://mycentralstar.com/leukosis.

Erskine, R. J., P. C. Bartlett, R. M. Byrem, C. L. Render, C. Febvay, and J. T. Houseman. 2012a. Association between bovine leukemia virus, production, and population age in Michigan dairy herds. J. Dairy Sci. 95:727-734. https://doi.org/10.3168/jds.2011-4760.

Erskine, R. J., P. C. Bartlett, T. M. Byrem, C. L. Render, C. Febvay, and J. T. Houseman. 2012b. Using a herd profile to determine age-specific prevalence of bovine leukemia virus in Michigan dairy herds. Vet. Med. Intern. 2012:350374.

Erskine, R. J., P. C. Bartlett, M. Sabo, and L. M. Sordillo. 2011a. Bovine leukaemia virus infection in dairy cattle: Effect on serological response to immunization against J5 Escherichia coli bacterin. Vet. Med. Int. 2011:915747. https://doi.org/10.4061/2011/915747.

Erskine, R. J., C. M. Corl, J. C. Gandy, and L. M. Sordillo. 2011b. Effect of infection with bovine leukosis virus on lymphocyte proliferation and apoptosis in dairy cattle. Am. J. Vet. Res. 72:1059-1064. https://doi.org/10.2460/ajvr.72.8.1059.

Esteban, E. N., R. M. Thorn, and J. F. Ferrer. 1985. Characterization of the blood lymphocyte population in cattle infected with the bovine leukemia virus. Cancer Res. 45:3225-3230.

Gillet, N., A. Florins, M. Boxus, C. Burteau, A. Nigro, F. Vandermeers, H. Balon, A.-B. Bouzar, J. Defoiche, A. Burny, M. Reichert, R. Kettmann, and L. Willems. 2007. Mechanisms of leukemogenesis induced by bovine leukemia virus: prospects for novel antiretroviral therapies in human. Retrovirology 4:18. https://doi.org/ 10.1186/1742-4690-4-18.

Goff, J. P., and R. L. Horst. 1997. Physiological changes at parturition and their relationship to metabolic disorders. J. Dairy Sci. 80:1260-1268. https://doi.org/10.3168/jds.S0022-0302(97)76055 -7 .

Hillers, J. K., P. L. Senger, R. L. Darlington, and W. N. Fleming. 1984. Effects of production, season, age of cow, days dry, and days in milk on conception to first service in large commercial dairy herds. J. Dairy Sci. 67:861-867. https://doi.org/10.3168/jds.S0022 -0302(84)81378-8.

Kabeya, H., K. Ohashi, and M. Onuma. 2001. Host immune responses in the course of bovine leukemia virus infection. J. Vet. Med. Sci. 63:703-708. https://doi.org/10.1292/jvms.63.703.

Kehrli, M. E., B. J. Nonnecke, and J. A. Roth. 1989. Alterations in bovine lymphocyte function during the periparturient period. Am. J. Vet. Res. 50:215-220.

Kettmann, R., D. Portetelle, M. Mammerickx, Y. Cleuter, D. Dekegel, M. Galoux, J. Ghysdael, A. Burny, and H. Chantrenne. 1976. Bovine leukemia virus: An exogenous RNA oncogenic virus. Proc. Natl. Acad. Sci. USA 73:1014-1018. https://doi.org/10.1073/pnas .73.4.1014.
Kuczewski, A., K. Orsel, H. W. Barkema, D. F. Kelton, W. A. Hutchins, and F. J. U. M. van der Meer. 2018. Short communication: Evaluation of 5 different ELISA for the detection of bovine leukemia virus antibodies. J. Dairy Sci. 101:2433-2437. https://doi .org/10.3168/jds.2017-13626.

Mallard, B. A., J. C. Dekkers, M. J. Ireland, K. E. Leslie, S. Sharif, C. L. Vankampen, and L. Wagter. 1998. Alteration in immune responsiveness during the peripartum period and its ramification on dairy cow and calf health. J. Dairy Sci. 81:585-595. https://doi .org/10.3168/jds.S0022-0302(98)75612-7.

Norby, B., P. C. Bartlett, T. M. Byrem, and R. J. Erskine. 2016. Effect of infection with bovine leukemia virus on milk production in Michigan dairy cows. J. Dairy Sci. 99:2043-2052. https://doi.org/ 10.3168/jds.2015-10089.

Ohno, A., S. Takeshima, Y. Matsumoto, and Y. Aida. 2015. Risk factors associated with increased bovine leukemia virus proviral load in infected cattle in Japan from 2012 to 2014. Virus Res. 210:283290. https://doi.org/10.1016/j.virusres.2015.08.020.

Ohtsuka, H., M. Uematsu, Y. Saruyama, M. Ono, M. Kohiruimaki, T. Ando, and S. Kawamura. 2009. Age-related alterations in peripheral leukocyte population of healthy Holstein dairy cows during the pre-calving period. J. Vet. Med. Sci. 71:1121-1124. https://doi .org/10.1292/jvms.71.1121.

Ott, S. L., R. Johnson, and S. J. Wells. 2003. Association between bovine-leukosis virus seroprevalence and herd-level productivity on US dairy farms. Prev. Vet. Med. 61:249-262. https://doi.org/10 .1016/j.prevetmed.2003.08.003.

Putman, A. K., J. Brown, J. Gandy, L. Wisnieski, and L. M. Sordillo. 2018. Changes in biomarkers of nutrient metabolism, inflammation, and oxidative stress in dairy cows during the transition into the early dry period. J. Dairy Sci. 101:9350-9359. https://doi.org/ 10.3168/jds.2018-14591.

Reber, A. J., A. Lockwood, A. R. Hippen, and D. J. Hurley. 2006. Colostrum induced phenotypic and trafficking changes in maternal mononuclear cells in a peripheral blood leukocyte model for study of leukocyte transfer to the neonatal calf. Vet. Immunol. Immunopathol. 109:139-150. https://doi.org/10.1016/j.vetimm.2005.08 .014 .

Rola, M., and J. Kuzmak. 2002. The detection of bovine leukemia virus proviral DNA by PCR-ELISA. J. Virol. Methods 99:33-40. https://doi.org/10.1016/S0166-0934(01)00384-6.

Roland, L., M. Drillich, and M. Iwersen. 2014. Hematology as a diagnostic tool in bovine medicine. J. Vet. Diagn. Invest. 26:592-598. https://doi.org/10.1177/1040638714546490.

Seifi, H. A., S. J. Leblanc, K. E. Leslie, and T. J. Duffield. 2011. Metabolic predictors of post-partum disease and culling risk in dairy cattle. Vet. J. 188:216-220. https://doi.org/10.1016/j.tvjl.2010.04 .007 .

Simard, C., S. Richardson, P. Dixon, C. Belanger, and P. Maxwell. 2000. Enzyme-linked immunosorbent assay for the diagnosis of bovine leukosis: Comparison with the agar gel immunodiffusion test approved by the Canadian Food Inspection Agency. Can. J. Vet. Res. 64:101-106.

Sordillo, L. M., and V. Mavangira. 2014. The nexus between nutrient metabolism, oxidative stress and inflammation in transition cows. Anim. Prod. Sci. 54:1204-1214. https://doi-org.proxy1.cl .msu.edu/10.1071/AN14503.

Sordillo, L. M., and W. Raphael. 2013. Significance of metabolic stress, lipid mobilization, and inflammation on transition cow disorders. Vet. Clin. North Am. Food Anim. Pract. 29:267-278. https://doi .org/10.1016/j.cvfa.2013.03.002.

Sprecher, D. J., K. D. Pelzer, and P. Lessard. 1991. Possible effect of altered management practices on seroprevalence of bovine leukemia virus in heifers of a dairy herd with history of high prevalence of infection. JAVMA 199:584-588.

Stata. 2017. CI-Confidence intervals for means, proportions, and counts. Pages 325-343 in Stata Base Reference Manual. StataCorp LP, College Station, TX.

Swenson, C. L., R. J. Erskine, and P. C. Bartlett. 2013. Impact of bovine leukemia virus infection on neutrophil and lymphocyte con- 
centrations in dairy cattle. JAVMA 243:131-135. https://doi.org/ 10.2460/javma.243.1.131.

Tajima, S., Y. Ikawa, and Y. Aida. 1998. Complete Bovine Leukemia Virus (BLV) provirus is conserved in BLV-infected cattle throughout the course of B-cell lymphosarcoma development. J. Virol. 72:7569-7576. https://doi.org/10.1128/JVI.72.9.7569-7576.1998.

Trono, K. G., D. M. Pérez-Filgueira, S. Duffy, M. V. Borca, and C. Carrillo. 2001. Seroprevalence of bovine leukemia virus in dairy cattle in Argentina: Comparison of sensitivity and specificity of different detection methods. Vet. Microbiol. 83:235-248. https:// doi.org/10.1016/S0378-1135(01)00420-5.

Walsh, R. B., D. F. Kelton, S. K. Hietala, and T. F. Duffield. 2013. Evaluation of enzyme linked immunosorbent assays performed on milk and serum samples for detection of neosporosis and leukosis in lactation dairy cows. Can. Vet. J. 54:347-352.

White, T. L., and D. A. Moore. 2009. Reasons for whole carcass condemnations of cattle in the United States and implications for producer education and veterinary intervention. JAVMA 235:937941. https://doi.org/10.2460/javma.235.8.937.
Wisnieski, L., B. Norby, S. J. Pierce, T. Becker, J. C. Gandy, and L. M. Sordillo. 2019. Predictive models for early lactation diseases in transition dairy cattle at dry-off. Prev. Vet. Med. 163:68-78. https: //doi.org/10.1016/j.prevetmed.2018.12.014.

Wojdak-Maksymiec, K., J. Szyda, and T. Strabel. 2013. Parity-dependent association between $T N F-\alpha$ and $L T F$ gene polymorphisms and clinical mastitis in dairy cattle. BMC Vet. Res. 9:114. https:/ /doi.org/10.1186/1746-6148-9-114.

World Organisation for Animal Health (OIE). 2018. Manual of Diagnostic Tests and Vaccines for Terrestrial Animals: Chapter 2.4.10. Paris, France.

\section{ORCIDS}

B. Norby @ https://orcid.org/0000-0001-6323-8735

J. Gandy (으 https://orcid.org/0000-0003-0558-9611

T. M. Byrem (๑ https://orcid.org/0000-0002-5340-0935

L. M. Sordillo 우 https://orcid.org/0000-0001-8873-3134 